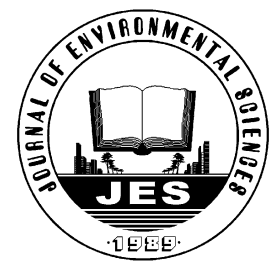

\title{
Ambient levels of atmospheric carbonyls in Beijing during the 2008 Olympic Games
}

\author{
Zhu $\mathrm{Xu}^{1,2}$, Junfeng Liu ${ }^{1}$, Yujie Zhang ${ }^{1,2}$, Peng Liang ${ }^{1,2}$, Yujing $\mathrm{Mu}^{1, *}$ \\ 1. Research Center for Eco-Environmental Sciences, Chinese Academy of Sciences, Beijing 100085, China. E-mail: xuzhu610@ 163.com \\ 2. Graduate School of Chinese Academy of Sciences, Beijing 100039, China
}

Received 25 December 2009; revised 11 March 2010; accepted 18 March 2010

\begin{abstract}
The measurements of atmospheric carbonyls concentrations in Beijing were conducted from 12 July to 8 October, 2008, covering the periods of the 2008 Olympic Games and Paralympic Games. Six carbonyls, including formaldehyde, acetaldehyde, acetone, butyraldehyde, valeraldehyde, and hexaldehyde, were identified in all air samples. The total average concentrations of these carbonyls before, during, and after traffic restriction were $(48.1 \pm 15.2),(36.6 \pm 14.5)$ and $(23.4 \pm 12.3) \mu \mathrm{g} / \mathrm{m}^{3}$, respectively. Compared with the period after traffic restriction, the distinct high concentrations of the carbonyls before and during traffic restriction were primarily ascribed to the remarkable contribution of photochemical reactions. With respect to our previous investigation in the summer of 2005 , the reductions of formaldehyde, acetaldehyde and acetone during traffic restriction period were about $64 \%, 47 \%$ and $27 \%$, respectively, indicating that the air cleaning actions adopted by the Chinese government for the two games were efficient. The lowest levels of atmospheric carbonyls and the extremely high composition proportion of acetone after the traffic restriction were mainly attributed to the long-term effect of the control measures for the two games.
\end{abstract}

Key words: Olympic Games; Paralympic Games; carbonyl compounds; traffic restriction; photochemical reactions; vehicular exhaust DOI: $10.1016 /$ S1001-0742(09)60261-8

\section{Introduction}

Carbonyls play an important role in atmospheric chemistry and urban air quality. They are directly discharged into the atmosphere from incomplete combustion of biomass and fossil fuel (Lipari et al., 1984), as well as formed as the major photochemical reaction products of volatile organic compounds (VOCs) in the atmosphere (Grosjean et al., 1996; Possanzini et al., 2002; Pang and $\mathrm{Mu}, 2006)$. Carbonyls are the pivotal source of radicals in the atmospheric chemistry relating to ozone production (Lary and Shallcross, 2000). In addition, some carbonyls are associated with adverse health impacts, because they have been recognized as carcinogenic and mutagenic character (Seinfeld and Pandis, 1997) and to be precursors of toxic, radical intermediates in the atmosphere (Possanzini et al., 2002).

The air quality in the metropolis of Beijing has aroused great attention from the world, especially during 2008 Olympic Games (Xie et al., 2008). Beijing municipal government adopted a series of pollution control measures to improve Beijing's air quality for the games by reducing the local emissions, such as the strict traffic restriction for motor vehicles (BOCOG, 2005; Hao and Wang, 2005). In the meantime, strict control strategies for air pollution

\footnotetext{
* Corresponding author. E-mail: yjmu@ rcees.ac.cn
}

were also carried out in all neighboring provinces and cities (Hebei Province, Tianjin City, Shanxi Province, Shandong Province and Inner Mongolia) (BOCOG, 2005). To evaluate the effect of the control measures, various air pollutants in Beijing were investigated by several institutes and universities in China during the two special games.

In this study, the ambient air concentrations of carbonyls in Beijing were measured from 12 July to 8 October, 2008, covering the periods of the 2008 Olympic Games and Paralympic Games. The objectives of this study were to provide scientific data for evaluating the effectiveness of the air cleaning actions adopted by the Chinese government for the two games, and to extend the database of carbonyls in the urban ambient air.

\section{Experimental method}

Air samples were collected on a rooftop (20 m above the ground level) in the Research Center for EcoEnvironmental Sciences which lies in the north of Beijing City between 4 th ring road and 5 th ring road. The sampling site is $4.82 \mathrm{~km}$ away from the Bird's Nest (Olympic Stadium) and surrounded by some residential areas, campuses and institutes. Two side roads with moderate traffic flow were about $120 \mathrm{~m}$ away from the sampling site.

To illustrate the effect of the traffic restriction (motor 
vehicles except taxies and buses were only allowed on road in odd or even day), air sampling was divided into three periods: before the traffic restriction (12-19 July), collected air samples for 5 days; during the traffic restriction (20 July-20 September), collected samples for 31 days; and after traffic restriction (21 September-8 October), collected samples for 6 days.

Carbonyls in the ambient air were sampled and determined using a technique on the basis of the EPA Method TO-11 A (US EPA, 1999). The detailed description of the method can be found in our previous paper of Pang and $\mathrm{Mu}$ (2006). Samples were collected at $2 \mathrm{hr}$ intervals from 7:00 to 21:00 (local time) for most sampling days. To reflect the nocturnal variations of carbonyls, air samples were also collected on several whole days during the traffic restriction. The sampling flow rate through the 2,4-dinitrophenylhenylhydrazine (DNPH)-coated Sep-Pak silica gel cartridges (Waters Inc., USA) was controlled by a rotameter with a needle valve of $0.8 \mathrm{~L} / \mathrm{min}$, which was calibrated by a soap flow meter in the laboratory. The samples were analyzed as their DNPH derivatives by a High Performance Liquid Chromatography (HPLC) system (Waters 2659 separations Module, Waters Inc., USA) with a Photodiode Array Detector at $360 \mathrm{~nm}$. The formed carbonyl-DNPH derivatives were separated on a Thermo ODS Hypersil column $(5 \mu \mathrm{m}, 250 \times 5.0$ $\mathrm{mm})$. Acetonitrile and water were used as mobile phases according to the following gradient: $0-12 \mathrm{~min}$ from $60 \%$ to $100 \%$ acetonitrile and $40 \%$ to $0 \%$ water; $12-14$ min from $100 \%$ to $60 \%$ acetonitrile and $0 \%$ to $40 \%$ water. The flow rate was $1.0 \mathrm{~mL} / \mathrm{min}$ and the injection volume was $10 \mu \mathrm{L}$. Relative standard deviations were less than $5.0 \%$ for all identified carbonyls based on the analysis results of five parallel samples.

\section{Results and discussion}

Six carbonyls were identified in all air samples, including formaldehyde, acetaldehyde, acetone, butyraldehyde, valeraldehyde, and hexaldehyde. The average concentrations and variation ranges of the identified carbonyls during the three investigated periods are summarized in Table 1. Among the carbonyls, acetone was always the most abundant compound during the three periods, concentration ranging between 3.5 and $26.7 \mu \mathrm{g} / \mathrm{m}^{3}$, followed by formaldehyde and acetaldehyde, with concentration ranges of $1.6-24.5 \mu \mathrm{g} / \mathrm{m}^{3}$ and $0.5-19.6 \mu \mathrm{g} / \mathrm{m}^{3}$, respectively. The concentrations of butyraldehyde, valeraldehyde and hexaldehyde were in the ranges of $0.1-15.1 \mu \mathrm{g} / \mathrm{m}^{3}, 0.1-$ $12.3 \mu \mathrm{g} / \mathrm{m}^{3}$ and $0.1-16.4 \mu \mathrm{g} / \mathrm{m}^{3}$, respectively. Our previous studies (Pang and Mu, 2006; Pang et al., 2009) at the same site revealed that the concentrations of atmospheric carbonyls in Beijing were the highest in August due to pronounced contribution of photochemical formation from VOCs. However, the concentrations of carbonyls in August, 2008 were much lower than those before the traffic restriction in July, such as the concentrations of formaldehyde, acetaldehyde, acetone, butyraldehyde, valeraldehyde and hexaldehyde were $46 \%, 28 \%, 10 \%$, $45 \%, 21 \%$ and $30 \%$, respectively lower in August than those before the traffic restriction. In view of the impact of the meteorological factors on atmospheric carbonyls, the average concentrations of carbonyls under clear days during the three periods were also calculated separately (data not shown), and the concentrations of the corresponding carbonyls in August were 49\%, 35\%, 12\%, 50\%, 24\% and $39 \%$, respectively lower than those before the traffic restriction. It is evident that the strict control measures, especially the traffic restriction in Beijing (the number of automobiles each day were cut down by 1.8 million, about $57.7 \%$ of the total vehicle number during the restriction (Liu et al., 2008)), were the important factors for reduction of atmospheric carbonyls. The control measures not only significantly reduced the direct carbonyls emissions from the controlled sources, but also largely lessened their atmospheric precursors, for example, the concentration of BTEX decreased by $50 \%$ during the traffic restriction (Liu et al., 2009). Further evidence could be seen from the obvious decrease of atmospheric CO (about 21\%-35\%) during the traffic restriction (Table 1).

The lowest concentrations of the carbonyls were observed after the traffic restriction when all the measures of control were cancelled, whereas the pollution levels of CO and other primary pollutants (such as BTEX, Liu et al., 2009) quickly recovered. These phenomena further indicated that the atmospheric carbonyls in Beijing were dominated by secondary formation. Due to the sunlight intensity and temperature in Beijing gradually decrease since September, the potential of photochemical conversion of VOCs to carbonyls was reduced correspondingly (Pang and $\mathrm{Mu}, 2006)$.

To illuminate the possible sources for the measured carbonyls in detail, the diurnal variations, the correlations

Table 1 Means and standard deviation of the carbonyls and CO during the three sampling periods (unit: $\mu \mathrm{g} / \mathrm{m}^{3}$ )

\begin{tabular}{|c|c|c|c|c|c|c|}
\hline & \multicolumn{2}{|c|}{$\begin{array}{l}\text { Before traffic restriction } \\
(7 / 12-7 / 19)(N=36)\end{array}$} & \multicolumn{2}{|c|}{$\begin{array}{c}\text { During traffic restriction } \\
(7 / 20-9 / 20)(N=203)\end{array}$} & \multicolumn{2}{|c|}{$\begin{array}{l}\text { After traffic restriction } \\
(9 / 21-10 / 8)(N=42)\end{array}$} \\
\hline & Mean \pm SD & Range & Mean \pm SD & Range & Mean \pm SD & Range \\
\hline Formaldehyde & $11.1 \pm 3.3$ & $5.8-19.0$ & $7.1 \pm 3.3$ & $1.6-24.5$ & $4.3 \pm 2.4$ & $1.7-15.9$ \\
\hline Acetaldehyde & $9.8 \pm 2.6$ & $6.0-15.1$ & $7.5 \pm 3.6$ & $0.5-19.6$ & $5.1 \pm 3.6$ & $1.5-19.3$ \\
\hline Acetone & $16.2 \pm 4.2$ & $10.9-26.7$ & $15.1 \pm 4.5$ & $4.7-24.5$ & $10.3 \pm 3.6$ & $3.5-18.5$ \\
\hline Butyraldehyde & $2.9 \pm 0.8$ & $1.6-5.1$ & $2.3 \pm 1.6$ & $0.1-15.1$ & $1.6 \pm 1.6$ & $0.1-8.6$ \\
\hline Valerldehyde & $4.8 \pm 3.1$ & $1.1-12.2$ & $2.5 \pm 2.2$ & $0.6-12.3$ & $1.3 \pm 0.5$ & $0.1-4.8$ \\
\hline Hexaldehyde & $3.3 \pm 1.2$ & $0.7-5.1$ & $2.1 \pm 2.6$ & $0.1-16.4$ & $0.8 \pm 0.6$ & $0.2-2.7$ \\
\hline $\mathrm{CO}$ & $815 \pm 214$ & $280-1840$ & $640 \pm 376$ & $300-2660$ & $978 \pm 794$ & $300-2580$ \\
\hline
\end{tabular}

$N$ : number of samples in statistical analysis. 
and the influence factors, as well as comparison with previous studies are further discussed in the following sections.

\subsection{Average diurnal variations of carbonyl compounds}

Figure 1 shows the average diurnal variations of carbonyls in Beijing during the three periods. The majority of the identified carbonyls exhibited similar diurnal variation pattern with peak values appearing in noon time or later afternoon, which could be interpreted as a consequence of photochemical formation of carbonyls through the photochemical oxidation of VOCs. The contribution of photochemical reactions to atmospheric carbonyls could also be clearly shown in a typical diel variation (Fig. 2). Possanzini et al. $(2002,2007)$ pointed out that photochemical formation accounted for $80 \%-90 \%$ of the atmospheric carbonyls in downtown of Rome during summer days. The contribution of photochemical conversion to atmospheric formaldehyde in Beijing was estimated to be more than
$70 \%$ during spring-autumn according to the report by Pang and $\mathrm{Mu}$ (2006).

To better reveal the effect of the control measures during the two games, the concentrations of formaldehyde measured during the whole period in this study are presented in Fig. 3. The peak values before the two games mostly happened at noontime of haze days, indicating that the haze days were in favor of the photochemical formation and accumulation of formaldehyde (Section 2.2). And the concentration of formaldehyde did not drop at the beginning of the traffic restriction due to frequent haze days. With the arrival of clear days, the concentration of formaldehyde decreased gradually, and achieved extremely minimum value during the two games. Because of the relatively lower sunlight intensity and temperature in autumn and the long-term effect of the control measures as discussed in Section 2.2, the concentration of formaldehyde reached the lowest level after the traffic restriction.

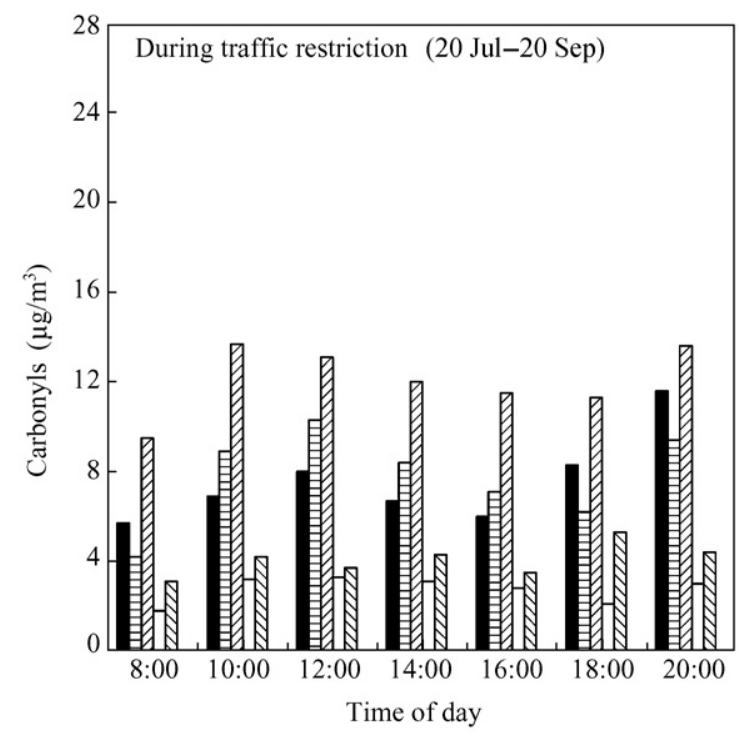

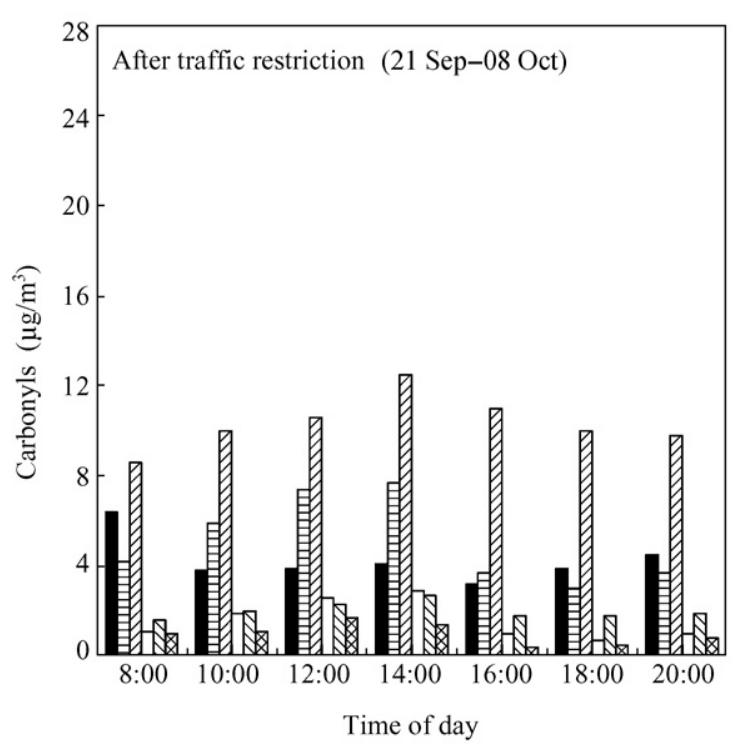

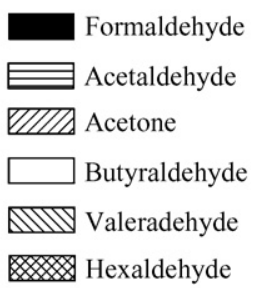

Fig. 1 Diurnal variations of averaged carbonyls levels in three sampling periods. 


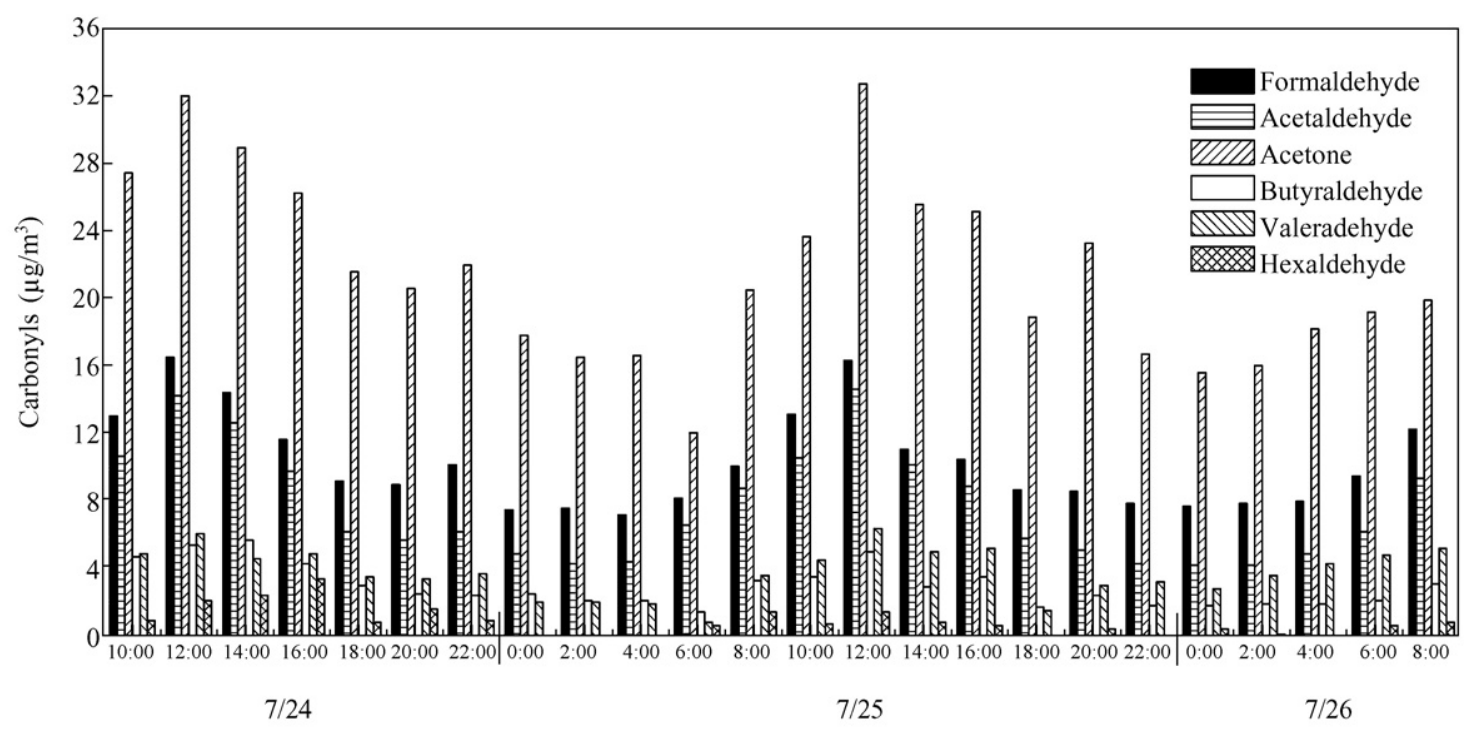

Fig. 2 Diel variations of carbonyls in Beijing during traffic restriction (24-26 July, 2008).

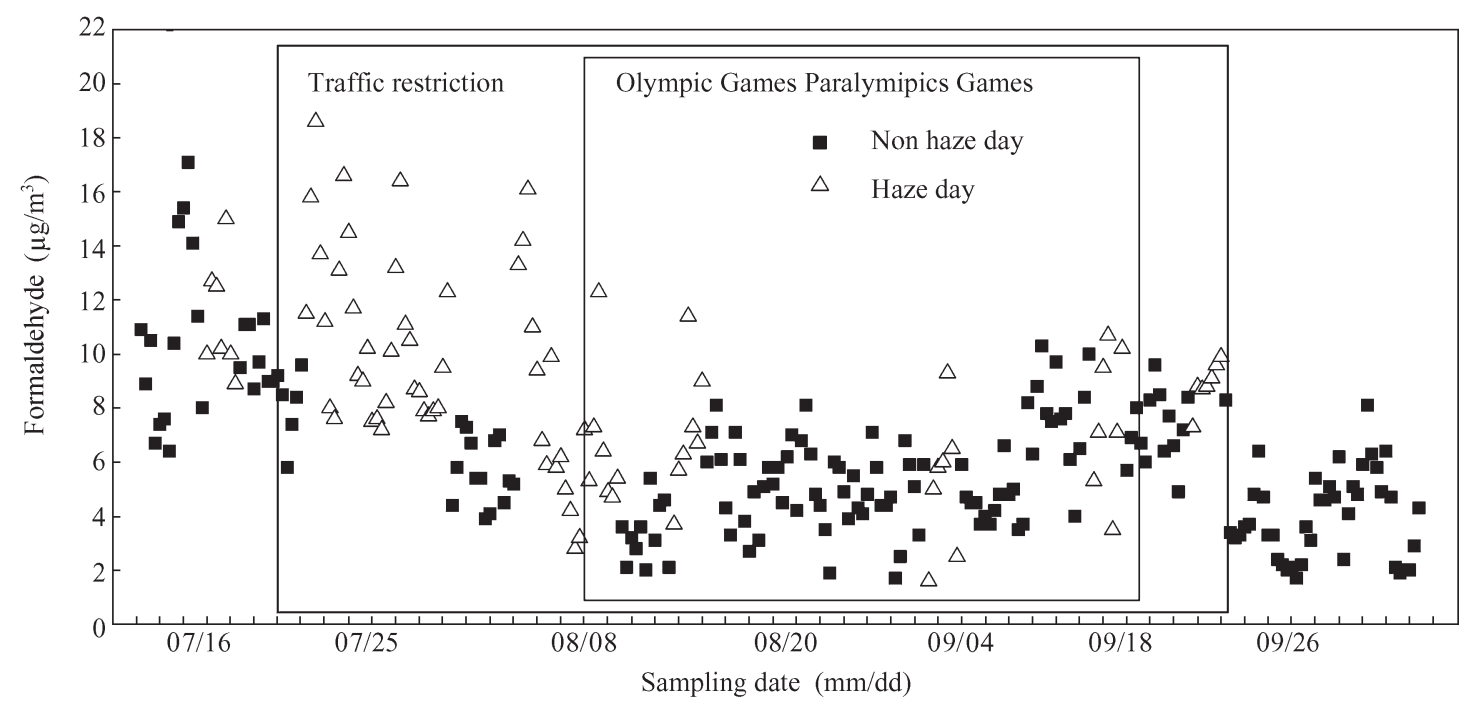

Fig. 3 Time series of formaldehyde from 12 July to 8 October in Beijing.

\subsection{Correlations among carbonyls and meteorological factors}

To clarify the effect of meteorological conditions, the correlations among the carbonyls and meteorological factors during the whole investigated period were analyzed (Table 2). With the only exception of hexaldehyde, significant correlations among the identified carbonyls were found, suggesting that they had common sources (Possanzini et al., 2002, 2007). As mentioned above, photochemical reaction of VOCs, especially in summer, was a predominant common source for them (Solberg et al., 2001; Possanzini et al., 2002; Pang and Mu, 2006).

The negative correlations between carbonyls and wind speed suggested that wind profited of diffusion of pollutants. The influence of wind speed on atmospheric carbonyls was clearly exhibited in Fig. 4 for two typical consecutive days. Cetin et al. (2003) pointed out that the strong wind defined as the speed higher than $5 \mathrm{~m} / \mathrm{sec}$ was helpful for fast dispersion of pollutants. However, wind speeds greater than $5 \mathrm{~m} / \mathrm{sec}$ during the whole investigated period only accounted for three days, and hence, only the influence of wind speed could not explain the large difference of the atmospheric carbonyls concentrations among the three investigated periods.

The significant positive correlations between carbonyls concentrations and temperature also reflected the contribution of photochemical reactions to the atmospheric carbonyls, because air temperature is closely relative to sunlight intensity.

Besides acetone, no significant correlations between carbonyls and humidity were found. The influence of humidity on atmospheric carbonyls concentrations is complex. The humidity is usually high after rain events or during haze days. The concentrations of atmospheric carbonyls after rain events were low due to scavenging by the rain; whereas they could increases under typical haze days because of accumulation or contribution from heterogeneous reactions. Scavenging of atmospheric 


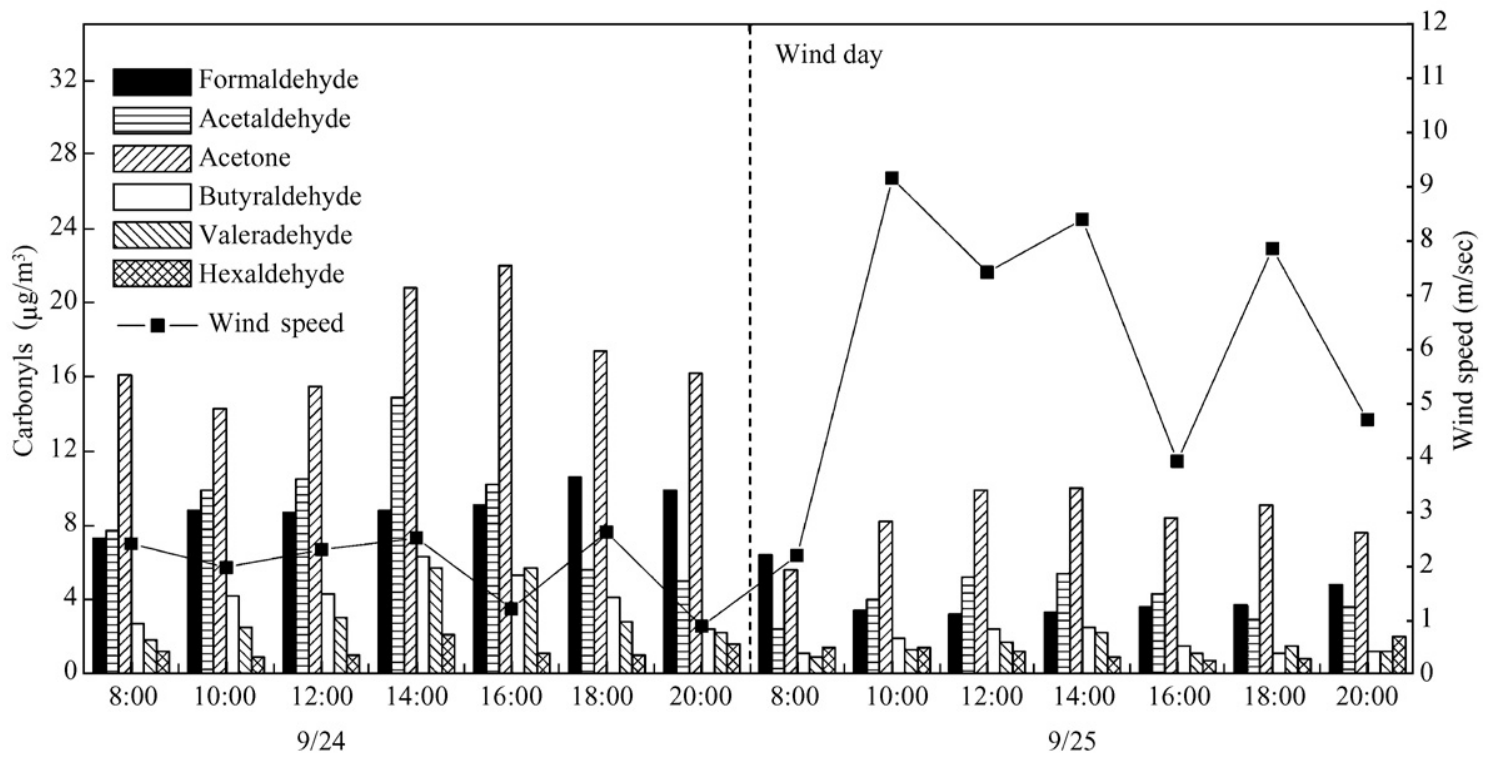

Fig. 4 Diurnal variations of carbonyls and wind speed in two consecutive days (24-25 September).

Table 2 Correlation coefficients between carbonyls and meteorology factors during the whole investigated period from 12 July to 8 October $(N=281)$

\begin{tabular}{|c|c|c|c|c|c|c|}
\hline & Formaldehyde & Acetaldehyde & Acetone & Butyraldehyde & Valeraldehyde & Hexaldehyde \\
\hline Formaldehyde & 1 & & & & & \\
\hline Acetaldehyde & $0.618 * *$ & 1 & & & & \\
\hline Acetone & $0.750 * *$ & $0.644 * *$ & 1 & & & \\
\hline Butyraldehyde & $0.548 * *$ & $0.571 * *$ & $0.586^{* * *}$ & 1 & & \\
\hline Valeraldehyde & $0.388 * *$ & $0.292 * *$ & $0.422 * *$ & $0.150^{*}$ & 1 & \\
\hline Hexaldehyde & $0.250^{* * *}$ & $0.194 * *$ & 0.129 & $0.451 * *$ & 0.051 & 1 \\
\hline Wind speed & $-0.158 * *$ & -0.115 & $-0.219 * *$ & $-0.142 *$ & -0.043 & -0.015 \\
\hline Temperature & $0.406^{* *}$ & $0.268 * *$ & $0.529 * *$ & $0.192 * *$ & $0.362 * *$ & $0.233 * *$ \\
\hline Humidity & 0.099 & 0.118 & $0.225^{* *}$ & -0.061 & 0.009 & -0.100 \\
\hline
\end{tabular}

** Correlation is significant at 0.01 level (2-tailed); * correlation is significant at 0.05 level (2-tailed).

carbonyls via precipitation was observed by comparison the concentrations of carbonyls before and after a rain event (with rainfall of $22.0 \mathrm{~mm}$ ) which lasted from the noon of 14 July to the afternoon of 15 July, 2008 (Fig. 5). Before the rain event (13 July), the total concentration of carbonyls was in the range of $42.6-72.4 \mu \mathrm{g} / \mathrm{m}^{3}$, however, it decreased to $33.8-49.3 \mu \mathrm{g} / \mathrm{m}^{3}$ after the rain event $(16$ July). To better illustrate the influence of haze days on atmospheric carbonyls, two typical diurnal variations of carbonyls on two consecutive days (23-24 July) with a

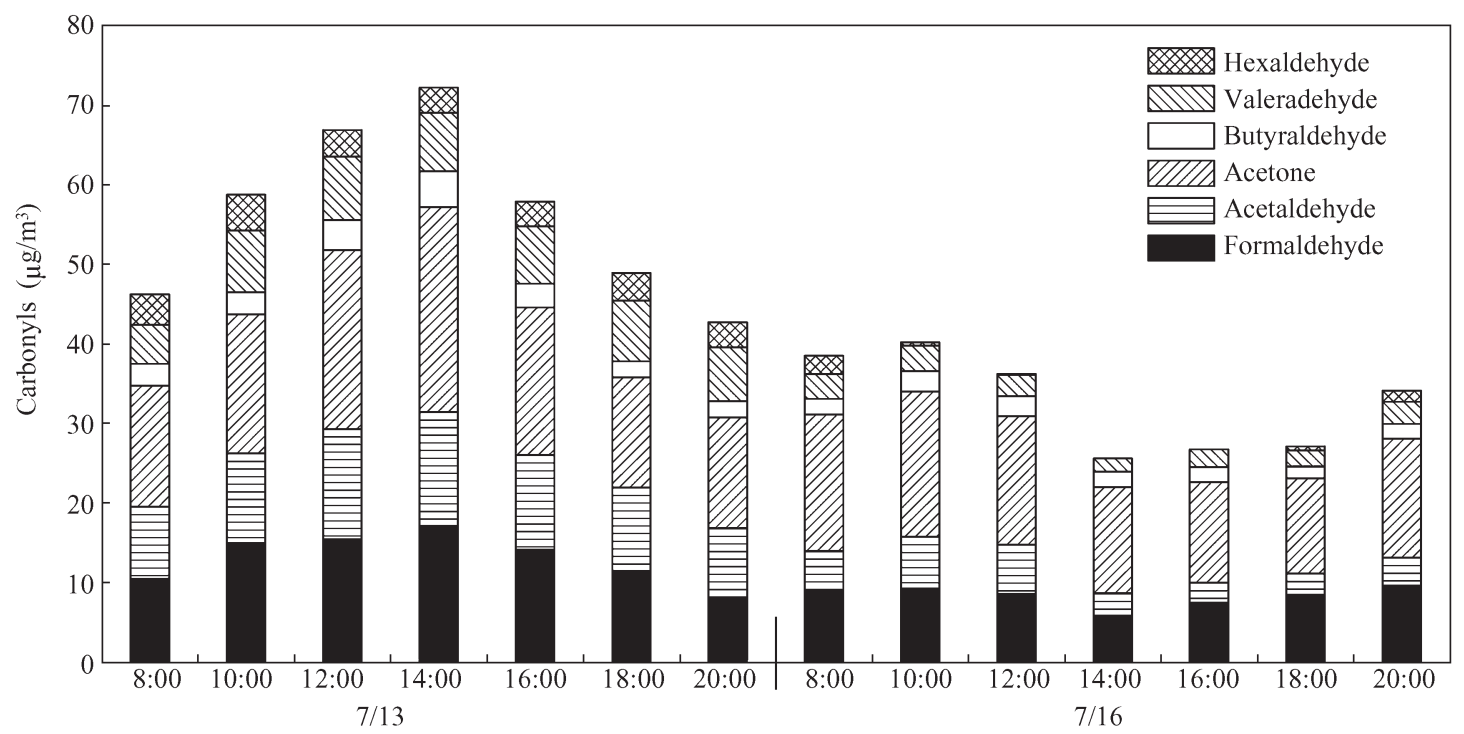

Fig. 5 Diurnal variation of carbonyls before (13 July) and after a rain event (16 July). 
clear day on 23 July and a haze day on 24 July are shown in Fig. 6. It is evident that the concentrations of the carbonyls were much higher in the haze day than those in the clear day. The stagnant air condition of haze days is favorable of the accumulation of pollutant (Chan et al., 2005; Mao et al., 2008), and resulted in relatively high concentration levels of the carbonyls. In the meantime, the photochemical reaction activity during haze days might be more pronounced than that during clear days, e.g., high concentration of HONO could be formed due to the heterogeneous reaction of $\mathrm{NO}_{2}$ with $\mathrm{H}_{2} \mathrm{O}$ on the abundant aerosol surfaces and resulted in high concentration of $\mathrm{OH}$ radicals which is the key species for atmospheric VOCs oxidation. $\mathrm{Su}$ et al. (2008) had observed the high HONO levels in the daytime during the summer haze days in Pear River Delta, Guangzhou, China. The maximal concentration values of the carbonyls at noon time and the high ethylbenzene/m,p- xylene ratios observed during haze days could be another evidence for the high photochemical reaction activity (Liu et al., 2009). The concentrations of the identified carbonyls in haze days during the whole investigation period in this study were 1.5 times higher than those in clear days. Lü et al. (2009) also found that the average total concentration of carbonyls in hazy days were higher than those in clear days by a factor of $1-4$.

\subsection{Ratios of formaldehyde/acetaldehyde}

The ratio of formaldehyde/acetaldehyde (F/A) has been widely used as an indicator of biogenic source for formaldehyde (Shepson et al., 1991). F/A ratios were reported to vary from about 1 in urban area (Ho et al., 2002; Feng et al., 2005; Pang and Mu, 2006) to about 10 in deciduous forest (Jacob and Wofsy, 1988; Shepson et al., 1991). High value of F/A ratio implied
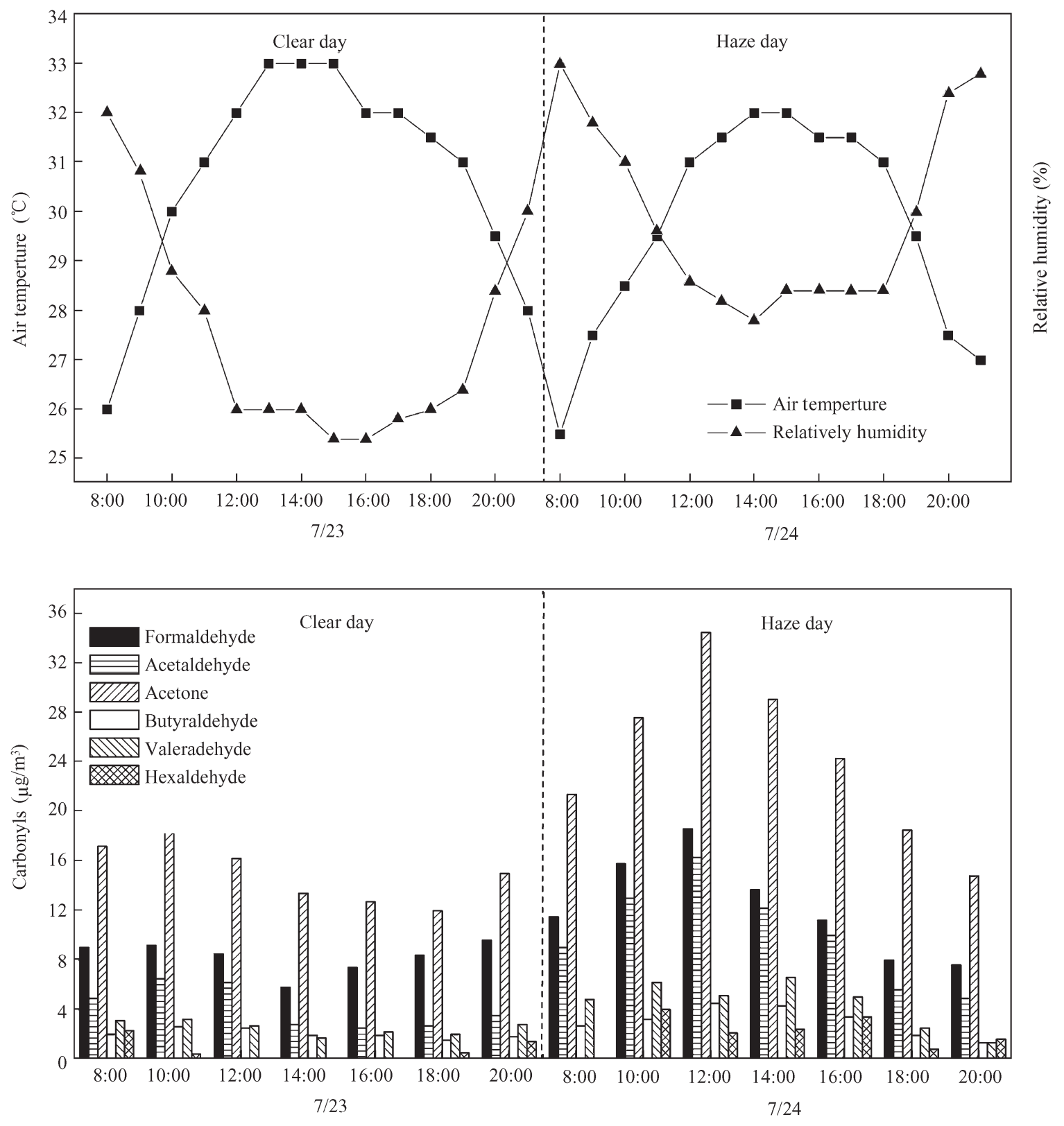

Fig. 6 Diurnal variations of carbonyls, air temperature and humidity in two consecutive days (clear day: 23 July; haze day: 24 July). 
that the photo-oxidation of natural hydrocarbons such as isoprene yields more formaldehyde than acetaldehyde (Lloyd et al., 1983; Shepson et al., 1991; Duane et al., 2002). The average F/A ratios before, during, and after the traffic restriction in this study were $1.11,0.96$, and 0.84 , respectively, suggesting that the anthropogenic activities were still dominant sources for atmospheric carbonyls even under such strict control measures during the two games. It should be mentioned that $\mathrm{F} / \mathrm{A}$ ratios investigated in this study during the summer time were about two times lower than our previous study (Pang and $\mathrm{Mu}, 2006$ ), indicating that the control measures might largely change the proportion of the different sources for atmospheric carbonyls, e.g., $57.7 \%$ of cars were reduced (Liu et al., 2008), while other sources, such as cooking and the buses fueled with diesel, were kept constant.

\subsection{Comparison with our previous study}

\subsubsection{Carbonyls' concentration levels during different periods}

To better evaluate the effect of the control measures on ambient carbonyls in Beijing, the levels of carbonyls during different investigation periods in this study were compared with our previous study at the same site and in the same season of 2005 (Pang and Mu, 2006). The average concentrations of formaldehyde, acetaldehyde and acetone before the traffic restriction (12-19 July) were about 43\%, $30 \%$ and $22 \%$, respectively lower than those measured in the same period of 2005 (Pang and Mu, 2006). As the meteorological conditions in July between the two years were almost identical (Table 3), the remarkable reduction of atmospheric carbonyls in July 2008 was ascribed to phasing out the vehicles with exhaust beyond the state standard (called yellow-marked cars) since 1 July, 2008. Although the number of yellow-marked cars $(357,000)$ accounted for about $10 \%$ of the total vehicles, the pollutants emitted from them were estimated to be more than $50 \%$ of the emission from vehicles (http://news.xinhuanet.com). Compared with the period in the summer of 2005 (Pang and Mu, 2006), the concentrations of formaldehyde, acetaldehyde and acetone during the traffic restriction decreased by $64 \%, 47 \%$ and $27 \%$, respectively. The yearly variation of meteorological conditions (Table 3) was insufficient to account for the large difference of the carbonyls' levels between the two years, and hence, the implementation of

Table 3 Comparison from July to October between 2005 and 2008 about average temperature, wind speed, intensity, and humidity, as well as rain events (http://www.wunderground.com/)

\begin{tabular}{llllll}
\hline $\begin{array}{l}\text { Date } \\
(\mathrm{yy} / \mathrm{mm} / \mathrm{dd})\end{array}$ & $\begin{array}{l}\text { Temper- } \\
\text { ature } \\
\left({ }^{\circ} \mathrm{C}\right)\end{array}$ & $\begin{array}{l}\text { Wind } \\
\text { speed } \\
(\mathrm{km} / \mathrm{hr})\end{array}$ & $\begin{array}{l}\text { Rain } \\
\text { events }\end{array}$ & $\begin{array}{l}\text { Intensity } \\
(\mathrm{mm})\end{array}$ & $\begin{array}{l}\text { Humidity } \\
(\%)\end{array}$ \\
\hline $2005 / 7$ & 26 & 9 & 9 & 83 & 76 \\
$2008 / 7$ & 26 & 7 & 8 & 66 & 77 \\
$2005 / 8$ & 25 & 8 & 9 & 87 & 85 \\
$2008 / 8$ & 25 & 7 & 10 & 88 & 76 \\
$2005 / 9$ & 21 & 7 & 3 & 15 & 70 \\
$2008 / 9$ & 20 & 5 & 6 & 50 & 73 \\
$2005 / 10$ & 14 & 9 & 2 & 1 & 57 \\
$2008 / 10 / 1-20$ & 13 & 8 & 4 & 19 & 64 \\
\hline
\end{tabular}

the strict control measures in 2008 could be in the saddle. Although the traffic restriction had cancelled since 20 Sep 2008 , the concentrations of formaldehyde, acetaldehyde and acetone after the traffic restriction decreased by $73 \%$, $68 \%$ and $38 \%$ relative to those in the autumn of 2005 . As mentioned above, the background concentrations of carbonyls and their precursors in a large region around Beijing would evidently decrease under the large scale air cleaning actions, which might have long-term effect on atmospheric carbonyls (Section 2.4.2). In addition, scavenging carbonyls by rain events was more remarkable during Sep-Oct in 2008 than in 2005, e.g., 10 rain events with total rainfall of $69 \mathrm{~mm}$ occurred during the period of Sep-Oct 2008, whereas only 5 rain events with rainfall of $16 \mathrm{~mm}$ happened during the same period in 2005 (Table 3).

\subsubsection{Composition patterns of carbonyls}

The comparison of percentage contributions of formaldehyde, acetaldehyde and acetone to their total concentration between this study during the three investigated periods and our previous study (Pang and $\mathrm{Mu}$, 2006) during the summer and the autumn are presented in Fig. 7. The proportion of acetone increased from $44 \%$ to $52 \%$ during the traffic restriction in comparison with that before the traffic restriction, while the proportion of formaldehyde decreased from $30 \%$ to $23 \%$, and the proportion of acetaldehyde decreased only a little (from $26 \%$ to $25 \%$ ). Because acetone has much longer lifetime (53 days due to $\mathrm{OH}$ consumption and approximately 60 days due to photolysis (Atkinson, 2000)) than those of formaldehyde and acetaldehyde (formaldehyde: 1.2 days due to $\mathrm{OH}$ consumption and 4 hours due to photolysis; acetaldehyde: 8.8 hours due to $\mathrm{OH}$ consumption and 6 days due to photolysis (Atkinson, 2000)), the significantly high proportion of acetone during the traffic restriction relative to that before the traffic restriction indicated that the levels of formaldehyde and acetaldehyde strikingly decreased and the background atmospheric acetone

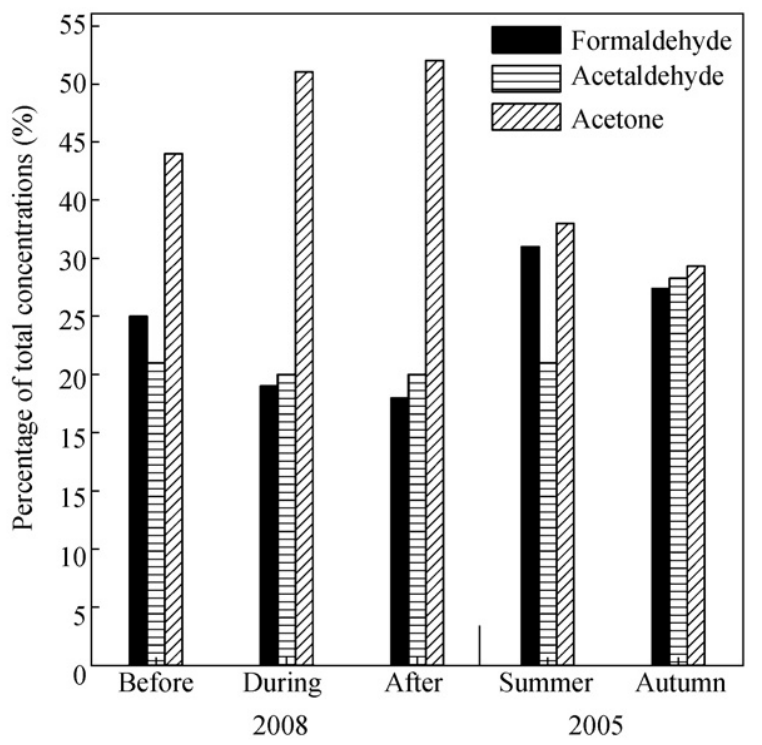

Fig. 7 Comparison of composition patterns of formaldehyde, acetaldehyde and acetone between this study and study from Pang and Mu (2006). 
Table 4 Comparison of mean concentrations of carbonyl compounds with other cities (unit: $\mu \mathrm{g} / \mathrm{m}^{3}$ )

\begin{tabular}{|c|c|c|c|c|c|c|c|c|}
\hline Location & $\begin{array}{l}\text { Sampling date } \\
\text { (yy/mm/dd) }\end{array}$ & $\begin{array}{l}\text { Formal- } \\
\text { dehyde }\end{array}$ & $\begin{array}{l}\text { Acetal- } \\
\text { dehyde }\end{array}$ & Acetone & $\begin{array}{l}\text { Butyral- } \\
\text { dehyde }\end{array}$ & $\begin{array}{l}\text { Valeral- } \\
\text { dehyde }\end{array}$ & $\begin{array}{l}\text { Hexal- } \\
\text { dehyde }\end{array}$ & Reference \\
\hline Beijing, China & $2008 / 7 / 12-20$ & 11.1 & 9.8 & 16.2 & 2.9 & 4.8 & 3.3 & This study \\
\hline Beijing, China & $2008 / 7 / 21-9 / 20$ & 7.1 & 7.5 & 15.1 & 2.3 & 2.5 & 2.1 & This study \\
\hline Beijing, China & $2005 / 6-8$ & 19.5 & 14.1 & 20.7 & - & - & - & Pang and $\mathrm{Mu}, 2006$ \\
\hline Beijing, China & $2004 / 7-8$ & 25.4 & 15.1 & - & - & - & - & Wang et al., 2007 \\
\hline Carmen, Mexico & $2004 / 8-9$ & 19.0 & 26.2 & 24.8 & 7.4 & - & - & Cerón et al., 2007 \\
\hline Guangzhou, China & $2003 / 6-9$ & 13.7 & 8.3 & 17.8 & 1.41 & 1.01 & 1.0 & Feng et al., 2005 \\
\hline Rio de Janeiro, Brazil & $2000 / 5-11$ & 10.8 & 10.4 & 4.1 & 0.5 & 0.3 & 0.3 & Grosjean et al., 2002 \\
\hline Beirut, Lebanon & $2004 / 8-10$ & 6.2 & 4.1 & 12.9 & - & - & - & Moussa et al., 2006 \\
\hline
\end{tabular}

over large scale made great contribution to the level of acetone in Beijing. The proportion patterns between the two periods during and after the traffic restriction were similar, but different in detail, that is, the proportion of formaldehyde further decreased after the traffic restriction, while those for acetaldehyde and acetone increased a little. As mentioned above, the photochemical activity gradually decreased after the traffic restriction (after September), and hence the contribution from the photo-oxidation of biogenic VOCs (especially for isoprene) to atmospheric formaldehyde reduced accordingly, e.g., the decrease of the proportion for formaldehyde was also observed from summer to autumn in our previous investigation (Fig. 7). In addition, the change of the composition of different sources after the traffic restriction (Section 2.4.1) might also partly account for the variation of the carbonyls' proportions. Due to the long lifetime of acetone, the extremely high proportion of acetone after the traffic restriction compared with that investigated in the autumn of 2005 (Fig. 7) suggested the long-term effect of the control measures on the atmospheric carbonyls in Beijing. Although similar composition pattern as that in the summer of 2005 (Fig. 7), the extremely high proportion of acetone before the traffic restriction could be ascribed to the elimination of yellow-marked cars since 1 July, 2008, e.g., prominent reduction of the atmospheric carbonyls during this investigated period against those in the summer of 2005 (as discussed at Section 2.4.1).

\subsection{Comparison with other cities}

Table 4 illustrates the comparisons of the concentrations of carbonyls detected in ambient air samples between Beijing and other cities (Grosjean et al., 2002; Feng et al., 2005; Pang and Mu, 2006; Moussa et al., 2006; Cerón et al., 2007; Wang et al., 2007). It is evident that the concentrations of formaldehyde and acetaldehyde in Beijing during the traffic restriction were much lower than those in the most cities. It should be noticed that the concentrations of valeraldehyde and hexaldehyde were extremely high comparing with other cities as well as Beijing investigated in our previous study. The outer-walls of the older buildings were decorated for the Games in July, and the emission from the solvents of the decorating materials was suspected to be responsible for the relatively high level of these carbonyls.

\section{Conclusions}

Based on these results, three conclusions could be derived: (1) the yellow-marked cars might make significant contribution to atmospheric carbonyls in Beijing, and should be ruled out to improve the air quality; (2) the controlling measures adopted by Chinese government for the 2008 Olympic Games were effective on reducing atmospheric carbonyls in Beijing, and had a long-term effect; (3) the meteorological conditions during haze days might be beneficial to carbonyls accumulation and photochemical formation.

\section{Acknowledgments}

This work was supported by the National Natural Science Foundation of China (No. 20977097, 40830101, 41075094), the Chinese Academy of Sciences (No. KZCX2-YW-Q02-03), the Platform Construction of Introducing Central Resources in Beijing (No. PXM2008_178305_06995) and the National Basic Research and Development Program (973) of China (No. 2010CB732304).

\section{References}

Atkinson R, 2000. Atmospheric chemistry of VOCs and NOx. Atmospheric Environment, 34(12-14): 2063-2101.

BOCOG (Beijing Organizing Committee for the Games of the XXIX Olympic Games), 2005. Green Olympics in Beijing. http://en.beijing2008.cn/bocog/environment/guidelines/ n214068405.shtml.

Cerón R M, Cerón J G, Muriel M, 2007. Diurnal and seasonal trends in carbonyl levels in a semi-urban coastal site in the Gulf of Campeche, Mexico. Atmospheric Environment, 41(1): 63-71.

Cetin E, Odabasi M, Seyfioglu R, 2003. Ambient volatile organic compound (VOC) concentrations around a petrochemical complex and a petroleum refinery. Science of the Total Environment, 312(1-3): 103-112.

Chan C Y, Xu X D, Li Y S, Wong K H, Ding G A, Chan L Y et al., 2005. Characteristics of vertical profiles and sources of $\mathrm{PM}_{2.5}, \mathrm{PM}_{10}$ and carbonaceous species in Beijing. Atmospheric Environment, 39(28): 5113-5124.

Duane M, Poma B, Rembges D, Astorga C, Larsen B R, 2002. Isoprene and its degradation products as strong ozone precursors in Insubria, northern Italy. Atmospheric Environment, 36(24): 3867-3879. 
Feng Y L, Wen S, Chen Y J, Wang X M, Lü H X, Bi X H et al., 2005. Ambient levels of carbonyl compounds and their sources in Guangzhou, China. Atmospheric Environment, 39(10): 1789-1800.

Grosjean D, Grosjean E, Moreira L F R, 2002. Speciated ambient carbonyls in Rio de Janeiro, Brazil. Environmental Science and Technology, 36(7): 1389-1395.

Grosjean E, Grosjean D, Fraser M P, Cass G R, 1996. Air quality model evaluation data for organics. 2. $\mathrm{C}_{1}-\mathrm{C}_{14}$ carbonyls in Los Angeles air. Environmental Science and Technology, 30(9): 2687-2703.

Hao J M, Wang L T, 2005. Improving urban air quality in China: Beijing case study. Journal of the Air $\mathcal{E}$ Waste Management Association, 55: 1298-1305.

Ho K F, Lee S C, Louie P K K, Zou S C, 2002. Seasonal variation of carbonyl compound concentrations in urban area of Hong Kong. Atmospheric Environment, 36(8): 1259-1265.

Jacob D J, Wofsy S C, 1988. Photochemistry of biogenic emissions over the Amazon forest. Journal of Geophysical Research, 93(D2): 1477-1486.

Lary D J, Shallcross D E, 2000. Central role of carbonyl compounds in atmospheric chemistry. Journal of Geophysical Research, 105(D15): 19771-19778.

Lipari F, Dasch J M, Scruggs W F, 1984. Aldehyde emissions from wood-burning fireplaces. Environmental Science and Technology, 18(5): 326-330.

Liu J F, Mu Y J, Zhang Y J, Zhang Z M, Wang X K, 2009. Atmospheric levels of BTEX compounds during the 2008 Olympic Games in the urban area of Beijing. Science of the Total Environment, 408(1): 109-116.

Liu M J, Mao B H, Huang Y, Zhang J P, Chen S K, 2008. Comparison of pre- \& post-Olympic traffic: a case study of several roads in Beijing. Journal of Transportation Systems Engineering and Information Technology, 8(6): 67-72.

Lloyd A C, Atkinson R, Lurmann F W, Nitta B, 1983. Modeling potential ozone impacts from natural hydrocarbons - I. Development and testing of a chemical mechanism for the NOx-air photooxidations of isoprene and $\alpha$-pinene under ambient conditions. Atmospheric Environment, 17(10): 1931-1950.

Lü H X, Cai Q Y, Wen S, Chi Y G, Guo S J, Sheng G Y et al., 2009. Carbonyl compounds in the ambient air of hazy days and clear days in Guangzhou, China. Atmospheric Research, 94(3): 363-372.

Mao T, Wang Y S, Jiang J, Wu F K, Wang X M, 2008. The vertical distributions of VOCs in the atmosphere of Beijing in autumn. Science of the Total Environment, 390(1): 97-
108.

Moussa S G, El-Fadel M, Saliba N A, 2006. Seasonal, diurnal and nocturnal behaviors of lower carbonyl compounds in the urban environment of Beirut, Lebanon. Atmospheric Environment, 40(14): 2459-2468.

Pang X B, Mu Y J, Lee X Q, Zhang Y J, Xu Z, 2009. Influences of characteristic meteorological conditions on atmospheric carbonyls in Beijing, China. Atmospheric Research, 93(4): 913-919.

Pang X B, Mu Y J, 2006. Seasonal and diurnal variations of carbonyl compounds in Beijing ambient air. Atmospheric Environment, 40(33): 6313-6320.

Possanzini M, Di Palo V, Cecinato A, 2002. Sources and photodecomposition of formaldehyde and acetaldehyde in Rome ambient air. Atmospheric Environment, 36(19): 3195-3201.

Possanzini M, Tagliacozzo G, Cecinato A, 2007. Ambient levels and sources of lower carbonyls at Montelibretti, Rome (Italy). Water, Air, and Soil Pollution, 183(1-4): 447-454.

Seinfeld J H, Pandis S N, 1997. Atmospheric Chemistry and Physics. Wiley, New York. 234-336.

Shepson P B, Hastie D R, Schiff H I, Polizzi M, Bottenheim J W, Anlauf K et al., 1991. Atmospheric concentrations and temporal variations of $\mathrm{C}_{1}-\mathrm{C}_{3}$ carbonyl compounds at two rural sites in central Ontario. Atmospheric Environment, 25A(9): 2001-2015.

Solberg S, Dye C, Walker S E, Simpson D, 2001. Long-term measurements and model calculations of formaldehyde at rural European monitoring sites. Atmospheric Environment, 35(2): 195-207.

Su H, Cheng Y F, Cheng P, Zhang Y H, Dong S F, Zeng L M, Wang X S et al., 2008. Observation of nighttime nitrous acid (HONO) formation at a non-urban site during PRIDEPRD2004 in China. Atmospheric Environment, 42(25): 6219-6232.

Wang B, Lee S C, Ho K F, 2007. Characteristics of carbonyls: Concentrations and source strengths for indoor and outdoor residential microenvironments in China. Atmospheric Environment, 41(13): 2851-2861.

Xie X, Shao M, Liu Y, Lu S H, Chang C C, Chen Z M, 2008. Estimate of initial isoprene contribution to ozone formation potential in Beijing, China. Atmospheric Environment, 42(24): 6000-6010.

US EPA (US Environmental Protection Agency), 1999. Method TO-11 A. Determination of formaldehyde in ambient air using adsorbent cartridge followed by high performance liquid chromatography (HPLC). Active sampling methodology. Research Triangle Park, NC, USA. 